\title{
CHALLENGES IN INDUSTRIALIZED RENOVATION OF APARTMENT BUILDINGS
}

\author{
Ergo Pikas ${ }^{1}$, Olli Seppänen ${ }^{2}$, Lauri Koskela ${ }^{3}$, and Antti Peltokorpi ${ }^{4}$
}

\begin{abstract}
Motivated by the European Green Deal framework, an ambitious 30-years long renovation strategy has been established in Estonia. This renovation strategy requires a substantial increase in the annual renovation capacity. New capabilities in terms of industrialization and digitalization of sustainable renovation processes need to be promoted. This explorative research aims to identify and understand existing practices, main barriers, and opportunities to industrialize and digitalize sustainable renovation of existing apartment buildings. Interviews and secondary data sources are used for data collection and analysis. Still many barriers exist, and more research and development in core elements of the industrialized renovation of apartment buildings is required. For example, further standardization of renovation products and processes is needed. Also, digitalization and automation of industrialized renovation of apartment buildings were the least developed core element.
\end{abstract}

\section{KEYWORDS}

Sustainability, renovation, industrialization, lean renovation, standardization.

\section{INTRODUCTION}

In the new European Green Deal framework, an ambitious objective to renovate existing building stock within the next 30 years has been established (Commission 2020a). To achieve the required volume at the reduced cost and lead time, the European Commission promotes the industrialization and digitalization of sustainable renovation of existing buildings (Commission 2020b).

However, the EU Commission's recommendations are eclectic and come short in providing a coherent framework and conceptualization for the renovation wave. Lean construction provides a conceptualization and framework to project-based renovation production systems. Kemmer (2018) proposed the renovation management method based on the transformation, flow, and value (TFV) theory. Kemmer's management method, however, did not address the industrialization and digitization of renovation processes as systemic means to improve renovation processes.

1 Assistant Professor, Department of Civil Engineering and Architecture, Tallinn University of Technology, Tallinn, Estonia, ergo.pikas@ taltech.ee, orcid.org/0000-0001-5691-685X

2 Associate Professor, Department of Civil Engineering, Aalto University, Espoo, Finland, olli.seppanen@aalto.fi, orcid.org/0000-0002-2008-5924

3 Professor, School of Art, Design and Architecture, University of Huddersfield, Huddersfield, UK, L.Koskela@hud.ac.uk, orcid.org/0000-0003-4449-2281

4 Assistant Professor, Department of Civil Engineering, Aalto University, Espoo, Finland, antti.peltokorpi@ aalto.fi, orcid.org/0000-0002-7939-6612 
This research aims to identify and understand existing practices, main barriers, and opportunities to develop the sustainable renovation of existing Soviet-time apartment buildings in Estonia. A qualitative approach is used, and interviews and secondary data sources are used to collect, analyze, and interpret data. The paper is structured as follows: (1) background study, (2) research method; (3) results; (4) discussion and conclusions.

\section{BACKGROUND}

The European Green Deal framework sets the policy to "building and renovating in an energy and resource-efficient way" (Commission 2020a). A roadmap for renovation has been established for improving the quality of the built environment for $80 \%$ of Estonian citizens by 2050 . The roadmap sets objectives to reduce thermal energy needs up to $70 \%$, electricity consumption up to $20 \%$, and CO2 emissions up to $90 \%$ (Kurnitski et al. 2020). According to the strategy, 141000 (27 000 public, 100000 single-family, and 14000 residential) buildings with a total area of 5.4 million $\mathrm{m}^{2}$ need to be renovated (Kurnitski et al. 2020). This requires at least 2 to 4 times increase in the sector's current renovation capacity.

During the Soviet time in Estonia, large suburban areas were rapidly built using standardized designs and industrialized (Meuser and Zadorin 2015) mineral-based construction products (Kurnitski et al. 2020). Timber is considered a substitute for mineral-based construction products to promote sustainable construction (Lazarevic et al. 2020): (1) to reduce the $\mathrm{CO}_{2}$ emissions (Balasbaneh et al. 2018; Skullestad et al. 2016); (2) to compress project lead time (Bertram et al. 2019); and (3) to tailor solutions that meet individual customer's needs (Wang et al. 2014). Timber-based construction also comes with the focus on industrial efficiency, underpinned by two broad strategies (Pelli 2021): (1) standardization of products and standardization of processes and (2) continuous improvement.

Renovation projects, however, have unique characteristics (e.g., existing assets and operations) and are subject to construction peculiarities (e.g., one-of-a-kind production, site production, and temporary organization) (Kemmer and Koskela 2020; Koskela 2000). Lean construction provides the conceptual framework of production and production management (Koskela 2000). Based on the TFV theory, Kemmer proposed a management method for renovation projects consisting of three elements (2018): including the conceptual model, the characterization of reconstruction projects, and the best practice guidelines for improving the reconstruction processes. However, the scope of Kemmer's (2018) study did not include the utility of industrialized practices and digitization of renovation processes.

The primary motivation for the industrialized renovation of buildings includes reducing lead time and cost and improving delivery and product quality. Also, industrialization helps to address construction peculiarities (Vrijhoef and Koskela 2005). It is a change in the construction system (Larsson et al. 2014), enabled by standardization of products and processes, underpinned by repetition, continuous learning, and experience feedback (Bertelsen 2004). Larsson et al. (2014) proposed the industrialized construction framework with five core elements and barriers. Although the framework was developed for infrastructure projects, the general conclusions also apply in the renovation of buildings.

The five core industrialization elements identified by Larsson et al. (2014) include: (1) Prefabrication related to product standardization strategy; and (2) integrated design and construction, (3) collaborative planning, (4) continuous improvement, and (5) 
digitalization and automation related to process standardization. Larsson et al. (2014) also identified five barriers to industrialization: (1) conservatism, (2) lack of repetition, (3) norms and codes, (4) procurement practices, and (5) regulatory framework.

In terms of the digitalization and automation of renovation processes, many relevant construction technologies are developed. For example, for mapping (e.g., scan to BIM, drone imaging, photogrammetry) (Wang et al. 2019) and sensing (e.g., physics-based sensors, computer vision) (Martinez et al. 2021) technologies are used to collect data. Building information modeling and simulation (Alwisy et al. 2019) and advanced data analytics (e.g., machine learning), utilizing collected data, are used to plan and design solutions. Building cloud-based common data environments (ISO 2018; Patacas et al. 2020) and digital twins (Sacks et al. 2020) could be used to manage data in the sustainable delivery of renovation projects.

\section{RESEARCH METHOD}

A case study was carried out to identify and understand existing practices, main barriers, and opportunities: the Akadeemia 5A student apartment building. The renovation project was completed in 2018, using industrialized wooden walls and roof panels to achieve a nearly zero energy building certification. Two additional interviews with the two timber building manufacturers in Estonia were carried out. These interviews were carried out to study their perspectives on the industrialized renovation of buildings.

Altogether seven semi-structured interviews were conducted. As part of the case study, five interviews with the client (two interviews), academic (one interview), designer (one interview), and manufacturer (one interview) were carried out. Project documents were also collected and used to analyze and interpret the best practices and problems. Two interviews from two different manufacturers included the project manager from the first manufacturer and the development manager from the second manufacturer. Interview questions were sent with an email invitation to take part in the interview. Participants were asked to prefill the interview answers before the online interview meeting.

\section{The Case Project Description}

The renovation project initiated by the Tallinn University of Technology established the objective to renovate an existing building into a nearly zero energy building using an industrialized construction approach. The five-story building (Soviet building type 121) with 80 apartments was built in 1986. The building was constructed using prefabricated large reinforced concrete floor and wall elements and sandwich elements for external walls. External walls could not be removed as these formed an important part of the existing structural scheme. The measured primary energy use was $300 \mathrm{kWh} /\left(\mathrm{m}^{2} \mathrm{a}\right)$. The building before and after renovation is shown in Figure 1.
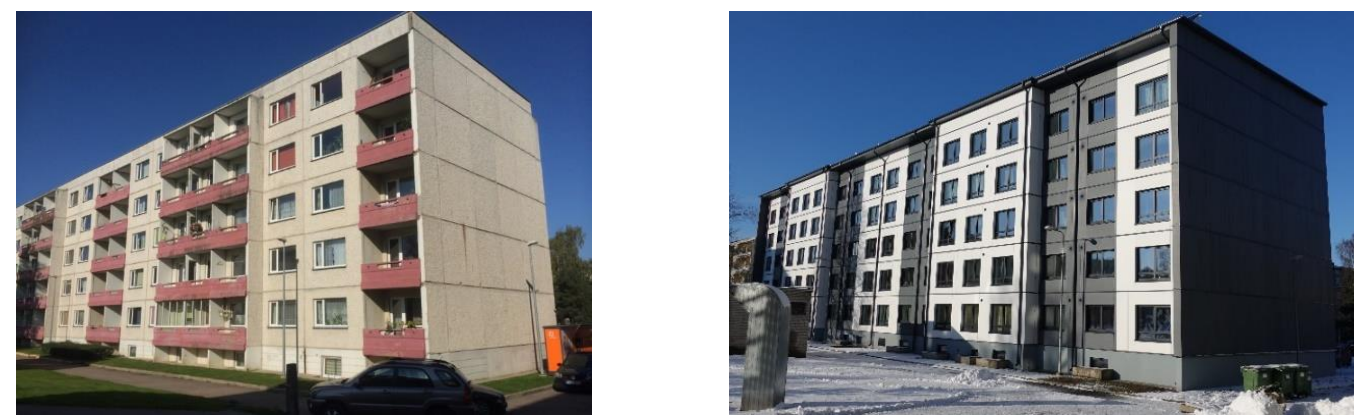

Figure 1. The building before (left) and after (right) renovation. 
The total cost of renovation was $822 € / \mathrm{m}^{2}$ of which $121 € / \mathrm{m}^{2}$ was spent on general construction works, $251 € / \mathrm{m}^{2}$ on finishing works, $334 € / \mathrm{m}^{2}$ on energy efficiency works and $116 € / \mathrm{m}^{2}$ on nearly zero energy building research related works. The scope of the energy performance works included the general works and renovation or construction of facade, roof, ventilation, and heating systems. Currently, costs for renovation are different and are rapidly changing. According to Kredex (established by the Ministry of Economic Affairs and Communications in 2001 to provide financial solutions) that has supported around 1200 renovation projects within the last ten years, today the traditional renovation costs between $300-350 € / \mathrm{m}^{2}$ and industrialized renovation between $400-450 € / \mathrm{m}^{2}$.

\section{RESULTS}

Based on the interviews and documents collected, lessons learned about the practices, barriers, and opportunities are summarized. The discussion is organized around the typical value chain phases of renovation projects: planning, design, manufacturing, logistics and transportation, and installation.

\section{Student Apartment Building Case}

\section{Practices}

According to interviewees, the main challenge was studying and measuring the building's existing conditions in the planning phase. Archived project documents were collected and studied to map the existing conditions. For mapping the building's geometric conditions, laser scanning was used to measure the envelope. The measured point deviation from the ideal reference wall plane with a minimum average distance to points was visualized in a color-coded manner. 50 sections were produced to analyze and communicate deviations. The locations and perimeters of 80 windows were checked manually.

In the design of industrialized renovation solutions, the solutions based on the existing geometric conditions, moisture safety, and energy performance to achieve the nearly zero energy building certification were prioritized. Due to the lack of standardized renovation solutions, technical solutions for wall and roof panels were developed with the university's researchers (the right picture in Figure 2). Wooden wall elements included embedded ventilation ducts and windows. Two measures were developed to address existing conditions' geometric variation and install new prefabricated walls. First, a new 3D connection was developed (left picture in Figure 2). Second, an additional buffer layer of insulation was added to the wooden wall panels' interior side (number 2 on the right picture in Figure 2). The total duration of the design process was six months.
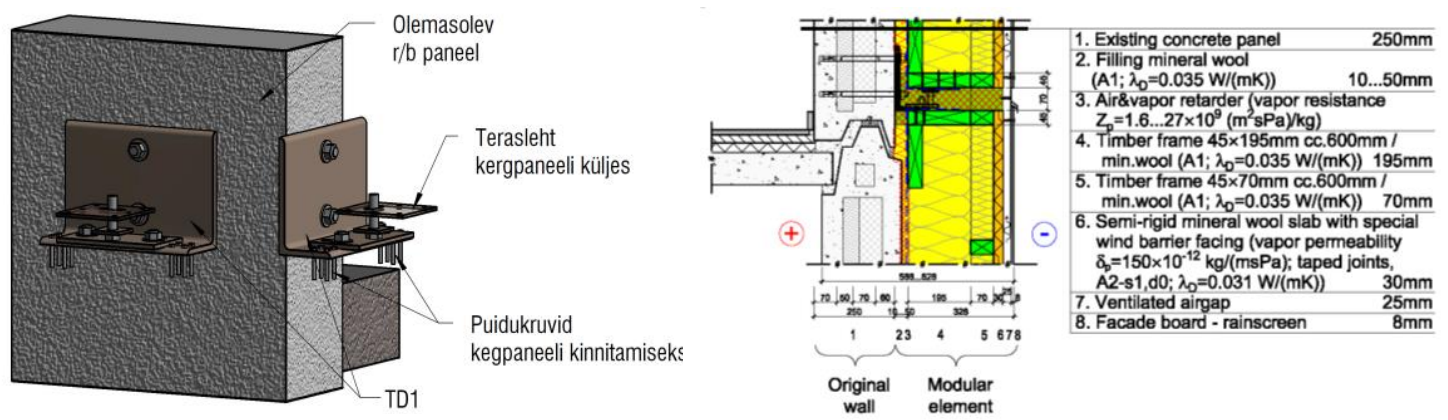

Figure 2. Newly developed 3D connection (left) and wall panel cross-section (right).

The manufacturer of wall and roof elements was also responsible for delivering shop drawings. In the factory, the volume and sequence of production were determined based 
on the installation sequence. Windows were installed to the wall elements in the factory to avoid the interior environment being exposed to the exterior environment. Also, ventilation ducts embedded in wall panels were installed in the factory.

For logistics and transportation, materials were packaged and delivered according to the installation sequence. On the site, trucks with cranes were used to transport wall panels for the lower floors. For higher floors, a separate mobile crane was used to lift elements for installation. A truck with a crane was preferred due to its faster lifting speed.

For installation, the trade partner was procured based on the lowest bid price. First, the foundation insulation works were carried out. The installation of a new technical room on the roof was completed in parallel. After that, the preparation for installing the wall and roof panels was carried out, including the installation of 3D connections, new roof trusses, and structures. Finally, wall and roof panels were installed, and joints were insulated and covered. The projected speed of installation was achieved after two-thirds of the panels were installed.

\section{Barriers}

Several problems in the planning phase were discovered. Finding proper project documents from the archive was more time-consuming than expected. The scanned data was not accurate enough, and some information was missing. As the building façade was scanned from the ground, some features (e.g., the bottom line of an exterior window) on the façade were hidden from the measurement by elements (e.g., window rain stain or balconies) extending out the façade. The problem is more extensive with the higher buildings. Also, different organizations and people measured the exterior and interior, which led to the situation that information was not fully compatible.

According to interviewees, designers lacked a specialized knowledge of moisture engineering and an understanding of industrialized processes in the design phase. The needs from a process perspective were not considered in the design. This was partly caused by the procurement model used by the client, which did not allow to involve the manufacturer and installer in the preliminary design and design development stages.

Some problems during the manufacturing were encountered. As nearly zero energy certification was targeted, much material was used to produce elements, which made elements heavy and challenging to handle in the factory. Also, the soft wind barrier used in the wall elements complicated the manufacturing of elements.

According to the manufacturer, there was not much space around the building regarding logistics and transportation, making the coordination of manufacturing, transportation, and installation crucial. Interviewees suggested keeping in mind also the weather conditions and elements' installation locations. When materials (e.g., insulation and timber) were transported to the site in large volumes, much of it was left unused for an extended period, which increased the possibility of weather damage to the materials.

In the installation phase, two major problems were faced. First, the inappropriate installation of connections on the exterior walls caused some wall elements not to fit between the new 3D connections on different floors, slowing down the construction process significantly. Handwork to fit the elements on the site was required. Tape measure and the string was used to determine the locations for installing the connections. However, the locations were not compared against the design model, and the distances between connections on different floors were also not verified.

Second, the trade partner did not follow the manufacturer's recommendations to structure and organize the installation works. The manufacturer recommended using three 
crews to improve flow: crew for installing elements, crew for sealing joints, and crew covering joints with façade plates. Instead, the trade partner installed all wall and roof elements first, and only after that started to seal exterior wall and roof joints. This delayed the learning significantly as the hard work of sealing wall and roof joints was discovered late in the process. It also appeared that the $5 \mathrm{~cm}$ gap between two wall panels (placed vertically on top of each other) is not a safe and effective solution for someone to stick their hand into the joint to insulate the gap between panels.

\section{Opportunities}

For addressing the laser-scanning challenges, interviewees suggested developing guidelines and implementing the 'scan to BIM' workflow to automatically or semiautomatically reconstruct the building's as-is model. There are already software tools (e.g., PointCab or EdgeWise) for that, and much research is done in this area.

Several design related recommendations were made regarding technical product solutions. It was suggested that more research and development on wall panel connections should be done to simplify installation. Also, with better technical solutions, the building's additional waterproofing and insulation and covering of wall panel joints could have been avoided and simplified.

A general recommendation to integrate the different phases of the renovation processes was suggested for improving the design process. Some interviewees also argued that designing renovation solutions should be automated. A knowledge library of renovation solutions and BIM technology could be used to automate design work. Also, the workflow from the early design phase to the later design phases and manufacturing could be improved. That is, going from scan to BIM and BIM to computer-aided manufacturing (CAM) was recommended to be studied.

Several opportunities concerning logistics and transportation were identified. Interviewees suggested developing proper lifting equipment, considering the manufacturing, transportation, and installation needs. It was also suggested that the justin-time and material kitting principles should be used to organize the transportation and installation of elements to avoid water and moisture damage.

Several recommendations to improve the installation process were made. Interview respondents suggested that the surveyor should have been involved throughout the installation process to double-check the locations of connections. It was also suggested to prototype the installation of wall panels on the site and use the production flow logic. The problem with the installed connections on existing exterior walls could have been discovered earlier through this approach. Namely, the connections were misplaced and placed into locations where there was a large volume of existing reinforcement, making the drilling of holes time-consuming. Instead of Excel, a general recommendation to use better software to coordinate and synchronize manufacturing, transportation, and installation was made.

\section{INTERVIEWS WITH TWO MANUFACTURERS}

Two additional interviews were conducted. The first manufacturer is currently delivering an industrialized renovation project in Saue, Estonia. The second is now preparing their industrialized renovation projects or products and services. According to the interviewees, their focus of developing industrialized solutions is to analyze business prospects, assess the renovation solutions' suitability for manufacturing, study automation possibilities, and digitalize processes. The main challenges are related to assuring high quality and efficiency. Also, according to interviewees, another main challenge is that traditional 
design and construction companies lack an understanding of industrialization and standardization and their role in cost-effectiveness and quality.

These companies are now analyzing the technical renovation solutions (e.g., studying fire safety and moisture safety requirements); collecting and digitalizing original project documents for Soviet time building types; preparing design templates and libraries; developing design and installation requirements for new assembly lines; and finding partners. Interviewees were also concerned with balancing the manufacturing supply with demand. In terms of logistics and transportation, participants think about packaging and storage of elements, access to sites, and developing special lifting equipment for elements. Regarding installation, problems foreseen are related to tolerance management and lack of skilled installation labor.

\section{Summary OF Practices, BARRIERS, AND OPPORTUNITIES}

Table 1 summarizes the practices, barriers, and opportunities for the industrialized and sustainable renovation of apartment buildings. Although there are many product and equipment specific problems, the majority seem to stem from the poor management of renovation projects. Establishing a proper management framework to enable continuous improvement within and across projects should be the priority. Next, the findings will be discussed within the industrialization framework proposed by Larsson et al. (2014).

Table 1. Summary of identified practices, barriers, and opportunities for the industrialized renovation of apartment buildings.

\begin{tabular}{|c|c|c|c|}
\hline & Practices & Barriers & Opportunities \\
\hline Planning & $\begin{array}{l}\text { Studying archived } \\
\text { project documents; } \\
\text { laser scanning }\end{array}$ & $\begin{array}{l}\text { Time-consuming to find; } \\
\text { poor practices of } \\
\text { scanning }\end{array}$ & $\begin{array}{c}\text { Digitalizing original } \\
\text { project documents; } \\
\text { implement Scan to BIM }\end{array}$ \\
\hline Design & $\begin{array}{l}\text { Prefabricated wall } \\
\text { and roof elements; } \\
\text { 3D connections }\end{array}$ & $\begin{array}{l}\text { Lack of knowledge and } \\
\text { understanding of } \\
\text { industrialization }\end{array}$ & $\begin{array}{l}\text { Standardization of } \\
\text { products; integration of } \\
\text { value chain; automation } \\
\text { and digitalization }\end{array}$ \\
\hline Manufacturing & $\begin{array}{l}\text { Sequencing; } \\
\text { windows and ducts } \\
\text { installed in the } \\
\text { factory }\end{array}$ & $\begin{array}{l}\text { Heavy elements; } \\
\text { inappropriate materials } \\
\text { for manufacturing }\end{array}$ & $\begin{array}{c}\text { Special lifting } \\
\text { equipment; proper } \\
\text { choice of materials }\end{array}$ \\
\hline $\begin{array}{l}\text { Logistics and } \\
\text { Transportation }\end{array}$ & $\begin{array}{l}\text { Sequencing; different } \\
\text { equipment }\end{array}$ & $\begin{array}{l}\text { Lack of space around } \\
\text { the building; weather }\end{array}$ & $\begin{array}{l}\text { Proper lifting equipment; } \\
\text { just in time delivery; } \\
\text { material kitting }\end{array}$ \\
\hline Installation & $\begin{array}{l}\text { Procurement of trade } \\
\text { partners based on } \\
\text { lowers bid price }\end{array}$ & $\begin{array}{c}\text { Installation of } \\
\text { connections; poor } \\
\text { installation management }\end{array}$ & $\begin{array}{l}\text { Involvement of } \\
\text { surveyors I the } \\
\text { installation process; } \\
\text { prototype installation; } \\
\text { implement flow }\end{array}$ \\
\hline
\end{tabular}

\section{DISCUSSION}

\section{BARRIERS TO INDUSTRIALIZATION}

Based on the literature review, case study, and interviews, improving the sustainable renovation of existing buildings requires a comprehensive and systemic approach. That is, barriers, sub-systems and aspects of delivering renovations projects need to be addressed simultaneously. Larsson et al. (2014) identified five barriers to industrialization. Except for legal framework, all other barriers were identified through the case study and 
interviews. Conservatism was identified in several instances of the case study and interviews: (1) client and manufacturer used traditional procurement methods; (2) instead of the production flow logic, the trade partner focused on optimizing resource consumption; (3) traditional design and construction companies do not understand industrialized processes and the importance of standardization.

Repetition in the renovation of existing apartment buildings is probably not going to be a significant issue. Although changes were made, the Soviet time apartment buildings' designs were highly standardized. Instead, the problem is the lack of standardized products and processes. Challenges related to the norms and codes were related to fireproofing, waterproofing, and moisture safety engineering during the construction and in the building made of timber roof and wall panels.

Procurement and contracting practices influence renovation projects' organization and the possibilities to implement and integrate industrialized solutions. The design-bid-build model limits the scope of implementing industrialized solutions as knowledge and experience exchange and integration are limited (Koskela and Vrijhoef 2001). Owners should promote collaborative procurement and contracting models.

In this study, the lack of competencies was also identified as one barrier to implementing industrialized construction. For example, designers' lack of moisture safety and manufacturing constraints competencies and knowledge caused several challenges.

\section{CORE ELEMENTS OF INDUSTRIALIZATION}

All interviewees are currently developing or interested in developing standardized solutions to (1) prefabricate. However, the Akadeemia 5A project demonstrated that more product development and standardization are needed. For example, problems related to manufacturability (weight, rigidity, lifting, and selection of materials), transportation, and assembly (installation, sealing joints, and covering joints with façade panels) should be addressed.

More elements are related to process standardization. Better (2) integration between design, manufacturing, and installation could have helped avoid problems with manufacturing, transportation, and installation of elements. More coupled integration between the design information flow from design to manufacturing, transportation, and installation, and constraints flow from manufacturing, transportation, and installation to design is required (Jensen et al. 2012). Proper procurement and contracting methods to enable integrated processes (e.g., improving installation speed and safety) and tolerance management (ensuring that elements fit on the site) need to be implemented by clients.

For just-in-time delivery, to avoid material storage and moisture damage on the site, (3) collaborative planning and control are required. This also requires a shift in thinking as demonstrated in the organization of work by trade partner from transformation to flow view of renovation projects. Prototyping during design, manufacturing, and at the beginning of installation to test the feasibility of solutions and plans is also necessary. Many problems in the Akadeemia 5A case could have been avoided, such as the complexity of drilling holes on site, installing roof panels, the insulating of joints and covering of joints could have been discovered earlier.

Rapid learning and (4) continuous improvement within and across projects are necessary for industrialized renovation. Continuous learning is enabled through product standardization, process integration, collaborative planning and control, facilitated by experience feedback. Hence, systemic learning needs to be integrated into the industrialized renovation of sustainable apartment buildings. 
Industrialized construction could be further facilitated by (5) digitalizing and automating processes. The digitalization level in industrialized renovation is low. Interviewees suggested that a scan to BIM framework should be adopted. Also, recommendations to automate design processes, utilizing BIM elements for standardized solutions, parametric design, and BIM to CAM were made. For information management in manufacturing, transportation, and installation, utilizing better digital solutions was recommended. The conceptual framework on the construction digital twin system has been proposed to address this limitation (Sacks et al. 2020). However, it has not yet been implemented nor tested in the context of renovation projects.

\section{CONCLUSIONS}

Large scale renovation brings forth challenges and opportunities for a systemic change in the construction industry. New capabilities for delivering industrialized renovation of sustainable buildings are needed. This research aimed to understand existing practices, main barriers, and industrialization opportunities for renovating existing apartment buildings. Several barriers need to be addressed for achieving new capabilities, and more research and development in core elements of the industrialized renovation of apartment buildings is required. Based on the literature review, case study, and interviews, improving the sustainable renovation of existing buildings requires a comprehensive and systemic management approach. Further standardization of renovation products and processes is needed, and digital and automation capabilities should be developed.

\section{REFERENCES}

Alwisy, A., Bu Hamdan, S., Barkokebas, B., Bouferguene, A., and Al-Hussein, M. (2019). "A BIM-based automation of design and drafting for manufacturing of wood panels for modular residential buildings." International Journal of Construction Management, Taylor \& Francis, 19(3), 187-205.

Balasbaneh, A. T., Marsono, A. K. B., and Khaleghi, S. J. (2018). "Sustainability choice of different hybrid timber structure for low medium cost single-story residential building: Environmental, economic and social assessment." Journal of Building Engineering, Elsevier, 20, 235-247.

Bertelsen, S. (2004). "Lean Construction: Where are we and how to proceed." Lean Construction Journal, 1(1), 46-69.

Bertram, N., Fuchs, S., Mischke, J., Palter, R., Strube, G., and Woetzel, J. (2019). Modular construction: From projects to products. McKinsey and Company, Chicago, USA, 34.

Commission, E. (2020a). The European Green Deal. COM(2019) 640 final, Official Journal of the European Union Brussels, Brussels, Belgium.

Commission, E. (2020b). A Renovation Wave for Europe - greening our buildings, creating jobs, improving lives [COM(2020) 662 final]. Communication from the Commission to the European Parliment, the Council, the European Economic and Social Committee and the Committee of the Regions, Brussels, Belgium.

ISO. (2018). "ISO 19650-1, Organization and Digitization of Information about Buildings and Civil Engineering Works, Including Building Information Modelling (BIM) - Information Management Using Building Information Modelling — Part 1: Concepts and Principles." International Standards Organisation.

Jensen, P., Olofsson, T., and Johnsson, H. (2012). "Configuration through the parameterization of building components." Automation in Construction, Elsevier, 23, 1-8. 
Kemmer, S. (2018). "Development of a Method for Construction Management in Refurbishment Projects." PhD Thesis, University of Huddersfield.

Kemmer, S., and Koskela, L. (2020). "Lean as an appropriate approach for managing production in refurbishment projects." Lean Construction: Core Concepts and New Frontiers, Routledge, 230.

Koskela, L. (2000). "An exploration towards a production theory and its application to construction.” Doctoral Dissertation, VTT Technical Research Centre of Finland, Espoo, Finland.

Koskela, L., and Vrijhoef, R. (2001). "Is the current theory of construction a hindrance to innovation?" Building Research \& Information, 29(3), 197-207.

Kurnitski, J., Kuusk, K., Kuivjõgi, H., Lihtmaa, L., Uutar, A., Pikas, E., Kalamees, T., and Simson, R. (2020). Hoonete rekonstrueerimise pikaajaline strateegia. Majandusja Kommunikatsiooniministeerium, Tallinn, Eesti.

Larsson, J., Eriksson, P. E., Olofsson, T., and Simonsson, P. (2014). "Industrialized construction in the Swedish infrastructure sector: core elements and barriers." Construction Management and Economics, Routledge, 32(1-2), 83-96.

Lazarevic, D., Kautto, P., and Antikainen, R. (2020). "Finland's wood-frame multi-storey construction innovation system: Analysing motors of creative destruction." Forest Policy and Economics, Forest-based circular bioeconomy: matching sustainability challenges and new business opportunities, 110, 101861.

Martinez, P., Barkokebas, B., Hamzeh, F., Al-Hussein, M., and Ahmad, R. (2021). "A vision-based approach for automatic progress tracking of floor paneling in offsite construction facilities." Automation in Construction, Elsevier, 125, 103620.

Meuser, P., and Zadorin, D. (2015). Towards a typology of Soviet mass housing: prefabrication in the USSR 1955-1991. DOM publishers Berlin.

Patacas, J., Dawood, N., and Kassem, M. (2020). "BIM for facilities management: A framework and a common data environment using open standards." Automation in Construction, Elsevier, 120, 103366.

Pelli, P. (2021). "Service innovation and sustainable construction: analyses of wood visà-vis other construction projects." Cleaner Engineering and Technology, 100061.

Sacks, R., Brilakis, I., Pikas, E., and Xie, H. S. (2020). "Construction with digital twin information systems." Data-Centric Engineering, 1, 26.

Skullestad, J. L., Bohne, R. A., and Lohne, J. (2016). "High-rise timber buildings as a climate change mitigation measure-A comparative LCA of structural system alternatives." Energy Procedia, Elsevier, 96, 112-123.

Vrijhoef, R., and Koskela, L. (2005). "Revisiting the Three Peculiarities of Production in Construction." 19-27.

Wang, Q., Guo, J., and Kim, M.-K. (2019). "An application oriented scan-to-BIM framework." Remote sensing, Multidisciplinary Digital Publishing Institute, 11(3), 365.

Wang, Z., Chen, L., Zhao, X., and Zhou, W. (2014). "Modularity in building mass customization capability: The mediating effects of customization knowledge utilization and business process improvement." Technovation, Elsevier, 34(11), 678-687. 